\title{
BONE DENSITY ASSESSMENTS IN MULTISLICE AND CONE-BEAM COMPUTED TOMOGRAPHY USING WATER, PLASTER OF PARIS AND MOTOR OIL PHANTOM
}

\author{
Haytham A Sedeek*, Akram A El-Awady**, Magdy K Mohamed***
}

\begin{abstract}
Background: The aim of the present study is to assess the image quality of multislice and cone-beam computed tomography using water, plaster of paris, and motor oil (WPO) phantom. Methods: A test object (radiographic phantom) were constructed, made up of 3 aligned acrylic cylinders filled with: (1) Distilled water, (2) Bubble free plaster, and (3) Motor oil. Subsequently, the cylinder was scanned with CBCT and MSCT using 3 FOV sizes with the cylinder positioned in the center of the FOVs. Test is made using multislice CT and 3 machines CBCT Planmeca, Vatech and Neotome. Results In the present study, Neotome, Planmeca and Vatech showed high significant measurements than MSCT in Plaster of Paris and Motor oil. The results of this study showed an excellent correlation between the voxel values from CBCT and the Hounsfield units derived from MSCT. Conclusion: In assessing density using CBCT, the $\mathrm{Y}=0.682(\mathrm{x})-161$ equation is therefore recommended.
\end{abstract}

\section{INTRODUCTION}

The quantity and the quality (density) of available bone influence the clinical success of dental implants. Computed tomography (CT) is an established method for acquiring bone images before performing dental implant surgery. It allows precise three-dimensional evaluation of anatomic structures and direct measurement of bone density, expressed in Hounsfield units (HU), characteristics that provide important information about the bone ${ }^{(1)}$.

Today, cone-beam computed tomography (CBCT) is increasingly replacing multislice CT (MSCT) in dentistry for evaluating mineralized tissues, because it provides adequate image quality associated with a lower exposure dose. Other advantages of CBCT are low cost, as compared with $\mathrm{CT}$, fast scanning time and lower number of image artifacts ${ }^{(2)}$. Several authors have reported the use of CBCT intensity values as a measurement to assess bone density ${ }^{(3-7)}$. However, other studies indicated that the $\mathrm{HU}$ derived from $\mathrm{CBCT}$ and from MSCT is not identical ${ }^{(8)}$. It was also believed that projection data discontinuity, image artifacts and the scatter levels produced by CBCT scanners can vary depending on the device, and can affect the accuracy of CBCT intensity values. This could make CBCT images unreliable for assessing bone density.

Unlike CT, the voxels of CBCT images do not represent absolute gray values (Hounsfield unit or HU). Various efforts have been taken to assess the reliability of this imaging modality in bone density measurements. Large amounts of scattered X-rays and artifacts are mentioned as the reasons for the

* BDS, 2010 G, Faculty of Dental Medicine, Misr Inetrnational University.

** Professor, Department of Oral Medicine, Periodontology, Diagnosis and Oral Radiology Faculty of Dental Medicine (Boys - Cairo) Al-Azhar University

*** Ass Professor, Department of Oral Medicine, Periodontology, Diagnosis and Oral Radiology Faculty of Dental Medicine (Boys - Cairo) Al-Azhar University 
unreliability of CBCT in evaluating bone mineral density ${ }^{(9)}$. CBCT scanners are operated at a lower $\mathrm{kVp}$ and $\mathrm{mA}$ than MSCT, resulting in a reduced signal-to-noise ratio ${ }^{(10)}$

The higher noise level will also cause more inconsistencies and a larger standard deviation of voxel gray values ${ }^{(11,12)}$. Additionally, as the volumeray beam in CBCT is proportionally larger than the highly collimated fan-beam in MSCT, the effect of these artifacts is ${ }^{(13)}$ However, other studies showed a high correlation between $\mathrm{CT}$ and $\mathrm{CBCT}$ gray values; therefore, it is suggested that voxel values of CBCT within certain constraints can be used to estimate bone mineral density ${ }^{(14-18)}$. In a study on bone quality assessment, CBCT was reported a valid technique for fractal analysis and bone area measurements but not for density evaluation. Although in this study the usefulness of CBCT in density measurements was not assessed clinically, it was reported that voxel values of CBCT are inappropriate for evaluating bone mineral density due to artifact-causing factors such as a large amount of scattering, beam hardening, and the heel effect. As the amount of scattered radiation is higher in CBCT in comparison to MSCT as mentioned before, the noise in the reconstructed images increases and the voxels do not represent the gray values as accurately as in MSCT. Beam hardening artifacts, due to the increase of the mean energy of the $\mathrm{X}$ ray beam when passing through the object, which will also alter the gray values, were mentioned as another factor. These factors are more severe in CBCT due to the use of a lower energy x-ray beam. The other artifact-causing factor reported in this study was the heel effect which is the angular non-uniformity of $\mathrm{x}$-ray energy in the beam Due to the larger width of the x-ray beam in CBCT this effect is worse than in multi detector $\mathrm{CT}^{(19)}$. The aim of this study is to evaluate the validity of the bone density value of CBCT device using real phantom. In this study, the bone density obtained using a MSCT scanner will be used as the gold standard.

\section{MATERIAL AND METHODS}

A test object (radiographic phantom) were constructed, made up of 3 aligned acrylic cylinders (diameter: $12 \mathrm{~mm}$, height: $57 \mathrm{~mm}$, wall thickness: $1.8 \mathrm{~mm}$ ) entirely filled with:

(1) Distilled water,

(2) Bubble free plaster, and

(3) Motor oil.

For the insertion of plaster into the cylinder, the plaster was manipulated with the correct proportion of distilled water, as recommended by the manufacturer. (Figure 1) Air bubbles were removed by vibration, and the cylinder were kept open at room temperature for 48 hours, until the complete curing of the plaster occurred. All cylinders were sealed inferior and superiorly by two $3.9 \mathrm{~mm}$ thick acrylic plates with $70340 \mathrm{~mm}$. The test object was then positioned in the center of an acrylic cylinder (diameter: $8 \mathrm{~cm}$, height: $8 \mathrm{~cm}$, wall thickness: $4 \mathrm{~mm}$ ) completely filled with distilled water. Subsequently, the cylinder was scanned with CBCT and MSCT using 3 FOV sizes with the cylinder positioned in the center of the FOVs. In the images obtained, each cylinder of the test object filled with distilled water, plaster, or motor oil were aligned vertically in the coronal and sagittal planes. The gray of the content of each cylinder were evaluated through 40 regions of interest (ROI) positioned in 40 axial cuts, spaced $0.5 \mathrm{~mm}$ apart, being 20 cuts above and 20 cuts below the vertical center of each cylinder. Each ROI will have an area of $25 \mathrm{~mm}^{2}$ (5 $35 \mathrm{~mm}$ ) and were positioned in the transversal center of the cylinders in the axial cuts. The CBCT and MSCT images were analyzed. Test is made using multislice CT and 3 machines CBCT Planmeca, Vatech and Neotome. 


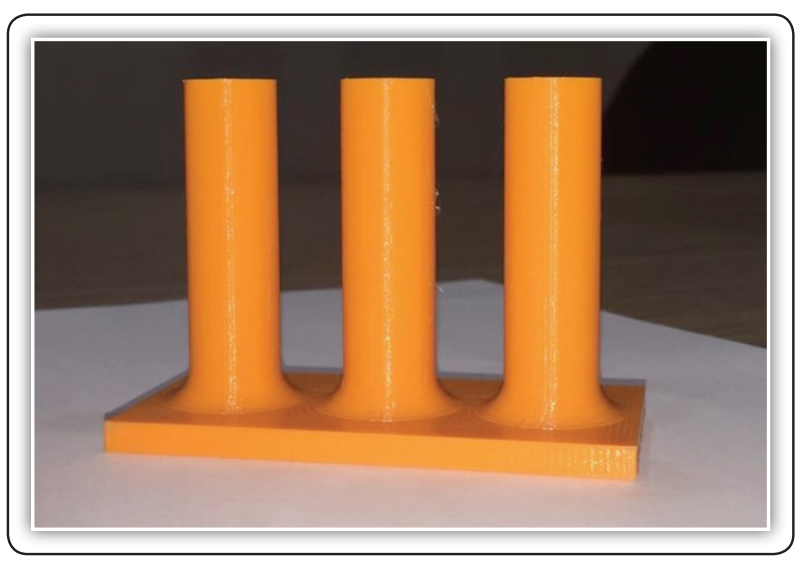

FIG (1) The phantom

\section{RESULTS}

In the present study, Neotome, Planmeca and Vatech showed high significant measurements than MSCT in Plaster of Paris and Motor oil. In water: there was no statistically significant difference between measurements in the all groups. Normally, gray values determined in CBCT examinations have been significantly different, greater, or smaller than those obtained in medical CT images. In this study, gray values in CBCT examinations were significantly different from those obtained in MSCT images with the same FOV size, being that CBCT showed lower values in most of the comparisons. The results showed a relationship between the gray values from CBCT and MSCT. The results of this study showed an excellent correlation between the voxel values from CBCT and the Hounsfield units derived from MSCT. Based on the Hounsfield units of phantom the formula converting the gray values from CBCT to the equivalent bone mineral density was determined as: $\mathrm{Y}=0.682(\mathrm{x})-161$, where $\mathrm{Y}=$ bone mineral density and $\mathrm{X}=\mathrm{CBCT}$ gray value.

TABLE (L): Comparison between the different studied groups according to different parameters

\begin{tabular}{|c|c|c|c|c|c|c|c|}
\hline & & MSCT & FOV 12x9 & FOV 10x10 & FOV $8 \times 8$ & $\mathbf{F}$ & p \\
\hline \multirow{11}{*}{ 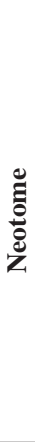 } & Plaster of paris & & & & & \multirow{5}{*}{$8.924^{*}$} & \multirow{5}{*}{$0.001^{*}$} \\
\hline & Median (Min. - Max.) & $1064(980-1457)$ & $2164(1186-2641)$ & $2374(1824-2947)$ & $2142(1909-2536)$ & & \\
\hline & Mean \pm SD & $1119.2 \pm 192.71$ & $2092.4 \pm 576.24$ & $2290 \pm 455.1$ & $2198.8 \pm 291.9$ & & \\
\hline & $\mathbf{p}_{1}$ & & $0.008^{*}$ & $0.002^{*}$ & $0.003^{*}$ & & \\
\hline & Sig. bet. grps & \multicolumn{4}{|c|}{$\mathrm{p}_{2}=0.868, \mathrm{p}_{3}=0.975, \mathrm{p}_{4}=0.984$} & & \\
\hline & Motor oil & & & & & \multirow{3}{*}{1.213} & \multirow{3}{*}{0.337} \\
\hline & Median (Min. - Max.) & $-168(-172-165)$ & $-147(-217--76)$ & $-207(-261--125)$ & $-197(-234--160)$ & & \\
\hline & Mean $\pm \mathrm{SD}$ & $-168.4 \pm 2.7$ & $-153.92 \pm 52.80$ & $-192.6 \pm 54.20$ & $-196.2 \pm 30.8$ & & \\
\hline & \multicolumn{7}{|l|}{ Water } \\
\hline & Median (Min. - Max.) & $6(-1-8)$ & $111(-17-242)$ & $25(-271-112)$ & $62(37-88)$ & \multirow{2}{*}{2.275} & \multirow{2}{*}{0.119} \\
\hline & Mean \pm SD & $5 \pm 3.54$ & $117.30 \pm 93.79$ & $-27.6 \pm 163.2$ & $63 \pm 24.3$ & & \\
\hline \multirow{13}{*}{ 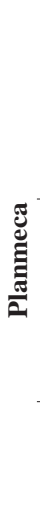 } & Plaster of paris & & & & & & \\
\hline & Median (Min. - Max.) & $1064(980-1457)$ & $1767(1605-1872)$ & $1987(1961$ - 1994) & $1804(1601-1866)$ & $4187^{*}$ & 0001 \\
\hline & Mean $\pm \mathrm{SD}$ & $1119.2 \pm 192.7$ & $1746.4 \pm 130.3$ & $1980.6 \pm 14$ & $1771.0 \pm 108.51$ & $41.04 /$ & $<0.001$ \\
\hline & $\mathbf{p}_{1}$ & & $<0.001^{*}$ & $<0.001^{*}$ & $<0.001^{*}$ & & \\
\hline & Sig. bet. grps & \multicolumn{6}{|c|}{$\mathrm{p}_{2}=0.048^{*}, \mathrm{p}_{3}=0.990, \mathrm{p}_{4}=0.085$} \\
\hline & Motor oil & & & & & & \\
\hline & Median (Min. - Max.) & $-168(-172--165)$ & $-187(-205--179)$ & $-175(-207--159)$ & $-158(-170--140)$ & $6170^{*}$ & $0.005^{*}$ \\
\hline & Mean \pm SD & $-168.4 \pm 2.7$ & $-188.8 \pm 10.4$ & $-178.8 \pm 20.2$ & $-155.6 \pm 11.5$ & & \\
\hline & $\mathbf{p}_{1}$ & & 0.095 & 0.585 & 0.417 & & \\
\hline & Sig. bet. grps & \multicolumn{6}{|c|}{$\mathrm{p}_{2}=0.615, \mathrm{p}_{3}=0.004^{*}, \mathrm{p}_{4}=0.049^{*}$} \\
\hline & \multicolumn{7}{|l|}{ Water } \\
\hline & Median (Min. - Max.) & $6(-1-8)$ & $1(-29-12)$ & $0(-38-39)$ & $1(-44-43)$ & \multirow{2}{*}{0.177} & \multirow{2}{*}{0.910} \\
\hline & Mean \pm SD & $5 \pm 3.5$ & $-4 \pm 17$ & $6 \pm 30.4$ & $0 \pm 34.8$ & & \\
\hline
\end{tabular}




\begin{tabular}{|c|c|c|c|c|c|c|c|}
\hline & & MSCT & FOV $12 \times 9$ & FOV 10x10 & FOV $8 \times 8$ & $\mathbf{F}$ & p \\
\hline \multicolumn{8}{|c|}{ Plaster of paris } \\
\hline & Median (Min. - Max.) & $1064(980-1457)$ & $1765(1641-1887)$ & $1130(914-1250)$ & $1916(1795-2069)$ & \multirow{4}{*}{$46.50^{*}$} & \multirow{4}{*}{$<0.001^{*}$} \\
\hline & Mean \pm SD & $1119.2 \pm 192.7$ & $1774.8 \pm 108.5$ & $1115 . \pm 131.9$ & $1918 \pm 106.9$ & & \\
\hline & $\mathbf{p}_{1}$ & & $<0.001^{*}$ & 1.000 & $<0.001^{*}$ & & \\
\hline & Sig. bet. grps & \multicolumn{4}{|c|}{$\mathrm{p}_{2}<0.00 \mathrm{I}^{*}, \mathrm{p}_{3}=0.394, \mathrm{p}_{4}<0.001^{*}$} & & \\
\hline \multicolumn{8}{|c|}{ Motor oil } \\
\hline & Median (Min. - Max.) & $-168(-172--165)$ & $-146(-200--121)$ & $-346(-412--335)$ & $-295(-316--259)$ & $70557^{*}$ & $-0001^{*}$ \\
\hline 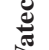 & Mean \pm SD & $-168.4 \pm 2.7$ & $-154 \pm 31.8$ & $-360.8 \pm 31.8$ & $-293.2 \pm 21.8$ & $79.55 \%$ & $<0.00 T^{\prime}$ \\
\hline & $\mathbf{p}_{1}$ & & 0.800 & $<0.001^{*}$ & $<0.001^{*}$ & & \\
\hline & Sig. bet. grps & \multicolumn{6}{|c|}{$\mathrm{p}_{2}<0.001^{*}, \mathrm{p}_{3}<0.001^{*}, \mathrm{p}_{4}=0.003^{*}$} \\
\hline \multicolumn{8}{|c|}{ Water } \\
\hline & Median (Min. - Max.) & $6(-1-8)$ & $-20(-52-9)$ & $-101(-302--38)$ & $-57(-110--40)$ & \multirow{4}{*}{$5.784^{*}$} & \multirow{2}{*}{$0.007^{*}$} \\
\hline & Mean \pm SD & $5 \pm 3.5$ & $-17.4 \pm 26.3$ & $-138.6 \pm 111.3$ & $-70.6 \pm 32.2$ & & \\
\hline & $\mathbf{p}_{1}$ & & 0.932 & $0.007^{*}$ & 0.224 & & \\
\hline & Sig. bet. grps & \multicolumn{5}{|c|}{$\mathrm{p}_{2}=0.024^{*}, \mathrm{p}_{3}=0.508, \mathrm{p}_{4}=0.305$} & \\
\hline
\end{tabular}

F: F for ANOVA test, Pairwise comparison bet. each 2 groups was done using Post Hoc Test (Tukey) $p: p$ value for comparing between the different studied groups $p_{l}: p$ value for comparing between MSCT and each other group $p_{2}: p$ value for comparing between FOV 12x9group and FOV 10x10group $p_{3}$ : $p$ value for comparing between FOV 12x9group and FOV 8x8group $p_{4}$ : $p$ value for comparing between FOV 10x10group and FOV 8x8group *: Statistically significant at $p \leq 0.05$

TABLE (2): Comparison between the studied groups according to HA

\begin{tabular}{|c|c|c|c|c|c|c|c|}
\hline & & & & & $\mathrm{P}$ & \multicolumn{2}{|c|}{$\begin{array}{c}\text { Equation: } \\
\text { Calculated density }\end{array}$} \\
\hline & & & Mean \pm SD & Mean & \multirow{5}{*}{$<0.001^{*}$} & $\begin{array}{c}Y=0.682 \\
(x)-161\end{array}$ & Mean \pm SD \\
\hline \multirow{4}{*}{ HA } & \multirow{3}{*}{ CBCT } & Neotome & $2088 \pm 56$ & \multirow{3}{*}{$1996 \pm 101$} & & 1263 & \multirow{4}{*}{1200} \\
\hline & & Planmeca & $1879 \pm 44$ & & & 1120 & \\
\hline & & Vatech & $2023 \pm 39$ & & & 1218 & \\
\hline & \multicolumn{2}{|c|}{ MSCT } & $1205 \pm 81$ & $1205 \pm 81$ & & & \\
\hline
\end{tabular}

TABLE (3): Correlation between Neotome, Planmeca and Vatech $(\mathrm{n}=10)$

\begin{tabular}{cccccc}
\hline & Neotome & Planmeca & Vatech & Average \\
\hline$\sum_{0}^{\infty}$ & $\mathbf{r}$ & $0.684^{*}$ & $0.684^{*}$ & $0.718^{*}$ & $0.701^{*}$ \\
\cline { 3 - 6 } & $\mathbf{p}$ & 0.029 & 0.029 & 0.019 & 0.024 \\
\hline
\end{tabular}

$$
\begin{aligned}
& r: \text { Pearson coefficient } \\
& *: \text { Statistically significant at } p \leq 0.05
\end{aligned}
$$

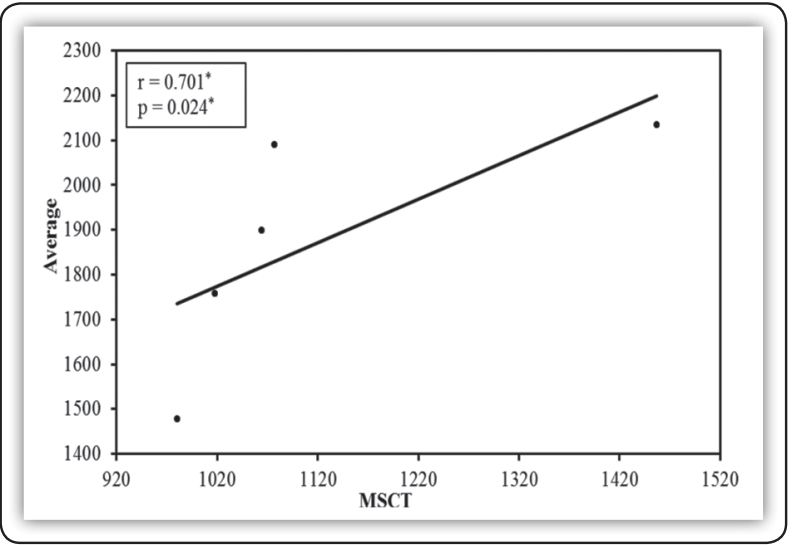

FIG (2) Correlation between MSCT with Average. 


\section{DISCUSSION}

The aim of the present study was to investigate the possible correlation between bone quality measurements of clinically applicable scanners in comparison with MSCT. CBCT has several advantages over MSCT in terms of more compact equipment, small footprint for the clinic, and relatively reduced scan costs. Additionally, lower radiation dose levels to the main organs of the head and neck region have been cited as one of the most important advantages of CBCT over MSCT (20-22). Due to these advantages, the use of this modality in dental implant planning is growing so fast and it is more accessible to the dental practitioners than before. Therefore, the validity of CBCT in bone quality assessment has been studied broadly. The majority of these studies have focused on the bone density measurement and found CBCT a reliable modality for bone density measurement (23-25). In the present study, Neotome, Planmeca and Vatech showed high significant measurements than MSCT in Plaster of Paris and Motor oil. The results showed a relationship between the gray values from CBCT and MSCT. The results of this study showed an excellent correlation between the voxel values from CBCT and the Hounsfield units derived from MSCT. Based on the Hounsfield units of phantom the formula converting the gray values from $\mathrm{CBCT}$ to the equivalent bone mineral density was determined as: $\mathrm{Y}=0.682(\mathrm{x})-161$, where $\mathrm{Y}=$ bone mineral density and $\mathrm{X}=\mathrm{CBCT}$ gray value.

To date, CBCT based BMD measurement has been used mainly to estimate bone properties for dental implantation ${ }^{(26-30)}$. The BMD measured from CBCT images showed a better predicting power to estimate cortical bone fracture than assessed by the conventional DXA images ${ }^{(31)}$. More applications are performed for the diagnosis of oral bone disease, improvement of orthodontic treatment, and maxillofacial surgery ${ }^{(32-34)}$. It is clear that higher resolution of 3D images can provide more useful information. For example, the partial volume effect can be reduced using a smaller voxel size in the image. However, if longer scanning time is required to obtain higher image resolution, the risk of high radiation exposure likely increases against the principle of "as low as reasonably achievable" (ALARA) radiation dose. As complete segmentation of bone voxels from non-bone voxels in the CT image with the current resolution can tremendously improve the capability of CT based analyses for both morphology and density, numerous studies have been attempted to develop innovative algorithms (35-38). Most commercialized CBCT software uses a global thresholding gray value to segment voxels. However, this simple method does not provide sufficient quality of images ${ }^{(39)}$.Further studies are still required to develop an optimal segmentation technology specific to individual CT images.

The high correlation between measured CBCT grey values and CT numbers in our study may confirms the possible potential of CBCT in radiographic density measurement. Many studies $^{(40,41)}$. found that strong positive correlations of the gray values of CBCT image with known density of reference materials and gray values obtained from the conventional clinical CT. The gray value of scanned specimens can be directly converted to the corresponding mineral density value using this calibration curve when the same CBCT scanner is used. Alternatively, a previous study found that the CBCT gray value strongly correlated with the CT attenuation coefficient $(\mu)$ of standard materials. Then, the corrected HU value of scanned materials was derived by estimating the attenuation values in the HU equation Eusing the correlation equation with the CBCT gray values. The corrected HU values were comparable between different $\mathrm{CBCT}$ scanners. Recently, clinical applicability of this HU correction was validated using intraoral phantoms for patients.

In an attempt to clarify and confirm the equation, phantoms of bone materials (hydroxyapatite) were scanned using 3 different CBCT. The CBCT gray 
value of scanned specimens (mean \pm SD: $1996 \pm 101$ ) directly converted to the corresponding mineral density value using the previous equation; $\mathrm{Y}=0.682$ (x) -161 . the resulted mineral density of phantoms

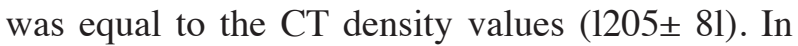
conclusion, Voxel gray values from CBCT deviate from actual HU units. However, a strong linear correlation exists, which may permit deriving actual HU units from CBCT.

\section{REFERENCES}

1. Aranyarachkul P, Caruso J, Gantes B, Schulz E, Riggs M, Dus I, Bone density assessments of dental implant sites: 2. quantitative cone-beam computerized tomography. Int $\mathbf{J}$ Oral Maxi fac Impl. 2005; 20(3):416-24.

2. Miracle AC, Mukherji SK. Conebeam CT of the head and neck, part 1: physical principles. AJNR Am J Neur o rad. 2009; 30(6): 1088-95.

3. Lee S, Gantes B, and Riggs M, Crigger M. Bone density assessments of dental implants sites: 3 . bone quality evaluation during osteotomy and implant placement. Int J Max fac Impl. 2007; 22(2):208-12.

4. Katsumata A, Hirukawa A, Okumura S, Naitoh M, Fujishita M, Ariji E, Relationship between density variability and imaging volume size in cone-beam computerized tomographic scanning of the maxillofacial region: an in vitro study. Oral Surg Oral Med Oral Pathol Oral Radiol Endod. 2009; 107(3):420-5.

5. Naitoh M, Aimiya H, Hirukawa A, Ariji E. Morphometric analysis of mandibular trabecular bone using cone beam computed tomography: an in vitro study. Int J Oral Max Ofac Impl. 2010; 25(6):1093-8.

6. Isoda K, Ayukawa Y, Tsukiyama Y, Sogo M, Matsushita Y, Koyano K. Relationship between the bone density estimated by cone-beam computed tomography and the primary stability of dental implants. Clin Oral Implants Res. 2012; 23(7):832-6.

7. Gonzlez-Garca R, Monje F. The reliability of cone-beam computed tomography to assess bone density at dental implant recipient sites: a histomorphometric analysis by micro-CT. Clin Oral Impl. Res. 2012; 17.

8. Arisan V, Karabuda ZC, Avsever H, Ozdemir T. Conventional Multi-Slice Computed Tomography (CT) and ConeBeam CT (CBCT) for Computer-Assisted Implant Placement. Part I: Re lationship of Radiographic Gray Density and Implant Stability. Clin Implant Dent Relat Res. 2012; 17.
9. Hua Y, Nackaerts O, Duyck J, Maes F, Jacobs R. Bone quality assessment based on cone beam computed tomography imaging. Clin Oral Implants Res 2009; 20: 767-71.

10. Schulze R, Heil U, Gross D, Bruellmann DD, Dranischnikow E, Schwanecke U, Artifacts in CBCT: a review. Septomaxillae Radiol 2011; 40: 265-73.

11. Araki K, Okano T. The effect of surrounding conditions on pixel value of cone beam computed tomography. Clin Oral Implants Res 2013; 24: 862-5.

12. Maes F, Collignon A, Vandermeulen D, Marchal G, Suetens P. Multimodality image registration by maximization of mutual information. IEEE Trans Med Imaging 1997; 16: 187-98.

13. Nackaerts O, Maes F, Yan H, Couto Souza P, Pauwels R, Jacobs R. Analysis of intensity variability in multislice and cone beam computed tomography. Clin Oral Implants Res 2011; 22: 873-9.

14. Aranyarachkul P, Caruso J, Gantes B, Schulz E, Riggs M, Dus I,. Bone density assessments of dental implant sites: 2. Quantitative cone-beam computerized tomography. Int J Oral Maxillofac Implants 2005; 20: 416-24.

15. Naitoh M, Hirukawa A, Katsumata A, Ariji E. Evaluation of voxel values in mandibular cancellous bone: relationship between cone-beam computed tomography and multislice helical computed tomography. Clin Oral Implants Res 2009; 20: 503-6.

16. Naitoh M, Hirukawa A, Katsumata A, Ariji E. Prospective study to estimate mandibular cancellous bone density using large-volume cone-beam computed tomography. Clin Oral Implants Res 2010; 21: 1309-13.

17. Nomura Y, Watanabe H, Honda E, Kurabayashi T. Reliability of voxel values from cone-beam computed tomography for dental use in evaluating bone mineral density. Clin Oral Implants Res 2010; 21: 558-62

18. Lagravère MO, Fang Y, Carey J, Toogood RW, Packota GV, Major PW. Density conversion factor determined using a cone-beam computed tomography unit NewTom QR-DVT 9000. Dento max fac Radiol 2006; 35: 407-9.

19. Bryant JA, Drage NA, Richmond S. Study of the scan uniformity from an i-CAT cone beam computed tomography denta1 imaging system. Dentomaxi11ofac Radio1 2008; 37: 365-74.

20. Carrafiello G, dizonno M., Colli V., Strocci S., Pozzi T., Leonardi A., et al Comparative study of jaws with multislice computed tomography and cone-beam computed tomography. La Radiologia medica 2010; 115: 600-11. 
21. Kau CH, Richmond S, Palomo JM, Hans MG. Three-dimensional cone beam computerized tomography in orthodontics. J. Ortho 2005; 32: 282-93.

22. White SC. Cone-beam imaging in dentistry. Health Physics 2008; 95: 628-37.

23. Nomura Y, Watanabe H, Honda E, Kurabayashi T. Reliability of voxel values from cone-beam computed tomography for dental use in evaluating bone mineral density. Clinical Oral Implants Research 2010; 21: 558-62.

24. Parsa A, Ibrahim N, Hassan B, Motroni A, van der Stelt $\mathrm{P}$, Wismeijer D. Reliability of voxel gray values in cone beam computed tomography for pre-operative implant planning assessment. The International Journal of Oral \& Maxillofacial Implants 2012; 27: 1438-42.

25. Reeves T, Mah P, McDavid WD. Deriving Hounsfield units using grey levels in cone beam CT: a clinical application. Dento max fac Rad 2012; 41: 500-8.

26. Benavides E, Rios HF, Ganz SD. Use of cone beam computed tomography in implant dentistry: the International Congress of Oral Implantologists consensus report. Impl Dent 2012;21:78-86.

27. Santiago RC, de Paula FO, Fraga MR. Correlation between miniscrew stability and bone mineral density in orthodontic patients. Am J Orthod Dentofacial Orthop 2009; 136:243-50.

28. Song YD, Jun SH, Kwon JJ. Correlation between bone quality evaluated by cone-beam computerized tomography and implant primary stability. Int J Oral Max fac Impl 2009; 24:59-64.

29. Aranyarachkul P, Caruso J, Gantes B. Bone density assessments of dental implant sites: 2. Quantitative conebeam computerized tomography. Int J Oral Max fac Impl 2005; 20:416-24.

30. Guerrero ME, Jacobs R, Loubele M. State-of-the-art on cone beam CT imaging for preoperative planning of implant placement. Clin Oral Investig 2006; 10:1-7.
31. Hsu JT, Chen YJ, Tsai MT. Predicting cortical bone strength from DXA and dental cone-beam CT. PLoS One 2012;7: e50008.

32. Hsu JT, Chang HW, Huang HL. Bone density changes around teeth during orthodontic treatment. Clin Oral Investig 2011; 15:511-9.

33. dos Anjos Pontual ML, Freire JS, Barbosa JM, Evaluation of bone changes in the temporomandibular joint using cone beam CT. Dentomaxillofac Radiol 2012;41:24-9.

34. Hohlweg-Majert B, Metzger MC, Kummer T, Morphometric analysis - Cone beam computed tomography to predict bone quality and quantity. J Craniomaxillofac Surg 2011; 39:330-4.

35. Loubele M, Maes F, Schutyser F. Assessment of bone segmentation quality of cone-beam CT versus multislice spiral CT: a pilot study. Oral Surg Oral Med Oral Pathol Oral Radiol Endod 2006; 102:225-34.

36. Nackaerts O, Depypere M, Zhang G. Segmentation of Trabecular Jaw Bone on Cone Beam CT Datasets. Clin Implant Dent Relat Res 2014.

37. Hangartner TN. Thresholding technique for accurate analysis of density and geometry in QCT, pQCT and microCT images. J Musculoskelet Neuronal Interact 2007; 7:9-16.

38. Klintstrom E, Smedby O, Moreno R. Trabecular bone structure parameters from $3 \mathrm{D}$ image processing of clinical multi-slice and cone-beam computed tomography data. Skel Rad 2014;43: 197-204.

39. Wang L, Chen KC, Gao Y. Automated bone segmentation from dental CBCT images using patch-based sparse representation and convex optimization. Med Phys 2014; 41:043503.

40. Mah P, Reeves TE, McDavid WD. Deriving Hounsfield units using grey levels in cone beam computed tomography. Dento max fac Rad 2010; 39:323-35.

41. Reeves TE, Mah P, McDavid WD. Deriving Hounsfield units using grey levels in cone beam CT: a clinical application. Dento max fac Rad 2012; 41:500-8. 